\title{
Retinal vasculitis in human T-lymphotropic virus type I associated myelopathy
}

\author{
K SASAKI, I MOROOKA, H INOMATA, N KASHIO, T AKAMINE, AND \\ M OSAME
}

From Miyazaki Prefectural Hospital, Kyushu University, and Kgoshima University, Japan

SUMMARY Human T-lymphotropic virus type I (HTLV-I) has been recently found to be associated with slowly progressive myelopathy. We have seen 12 patients with HTLV-I associated myelopathy (HAM), three of whom showed retinal vasculitis. In addition two patients had ocular symptoms of vitreous opacity. Retinal vasculitis in these patients appears to be phlebitis and sheathing of retinal veins in the periphery of the fundus.

Human T-lymphotropic virus type I (HTLV-I) was isolated from T-cell lymphoma and adult T-cell leukaemia ${ }^{2}$ and is now considered to be the causative agent of adult T-cell leukaemia/lymphoma. Recently HTLV-I was found to be associated with chronic myelopathy of unknown aetiology, that is, tropical spastic paraparesis (TSP) in equatorial countries, Martinique, Jamaica, ${ }^{3}$ off the pacific coast of Colombia, ${ }^{4}$ and Seychelles Island. ${ }^{5}$ Moreover, in south-western Japan, which is in a temperate zone, HTLV-I was found in patients with slowly progressive myelopathy. Osame et al suggested that the Japanese myelopathy, HTLV-I associated myelopathy (HAM), is a distinct clinical entity because it has not been found in a tropical area. ${ }^{6-8}$ It is believed that HAM is essentially the same as HTLV-I associated TSP, because their clinical features resemble each other. $^{78}$

The prevalence of HTLV-I carriers in the healthy population is about $10 \%$ in south-western Japan, and HTLV-I has been found to be transmitted by breast feeding, sexual contact, and blood transfusion. The proportion of HAM cases in the carrier group is estimated to be 1 to 2000 , and 556 patients with HAM have been registered so far throughout Japan. ${ }^{8}$ In our experience patients with HAM often complain of ocular symptoms. So far we have examined ophthalmologically 12 patients with HAM. Five were found to have ocular changes; retinal vasculitis was seen in three of them. To our knowledge retinal vasculitis in

Correspondence to Dr K Sasaki, Department of Ophthalmology, Miyazaki Prefectural Hospital, Kitatakamatsu-cho, Miyazaki 880, Japan. patients with TSP or HAM has not been reported previously. The present report describes three such patients.

\section{Case reports}

CASE I

A 58-year-old woman came to our clinic in 1981 with a six-year history of slowly progressive gait disturbance. she also had sensory and sphincter impairment. She had a history of an operation for pituitary tumour in 1979.

On the first visit to our clinic in 1981 her visual acuity was 20/20 in each eye. Funduscopic examination showed sheathing of the retinal veins and phlebitis in the periphery of the fundus with vitreous haze in both eyes. A slight visual field defect was observed on the temporal side of both eyes, probably due to residual defects from the previous resection of the pituitary tumour. The sheathing of the veins has gradually extended posteriorly towards the disc. In July 1987 the blood serum and cerebrospinal fluid (CSF) were found to be positive for antibodies to HTLV-I. Her husband was also seropositive for HTLV-I. In August 1987 she was started on corticosteroids orally, and the gait disturbance improved slightly. In November 1987 her visual acuity was $20 / 25$ in each eye. There were posterior subcapsular cataract and vitreous haze bilaterally, sheathing of the veins over the entire periphery of the fundus, obliteration of arteries, and optic atrophy in both eyes. A fluorescein angiogram showed macular oedema, disturbance of the pigment epithelium, and 


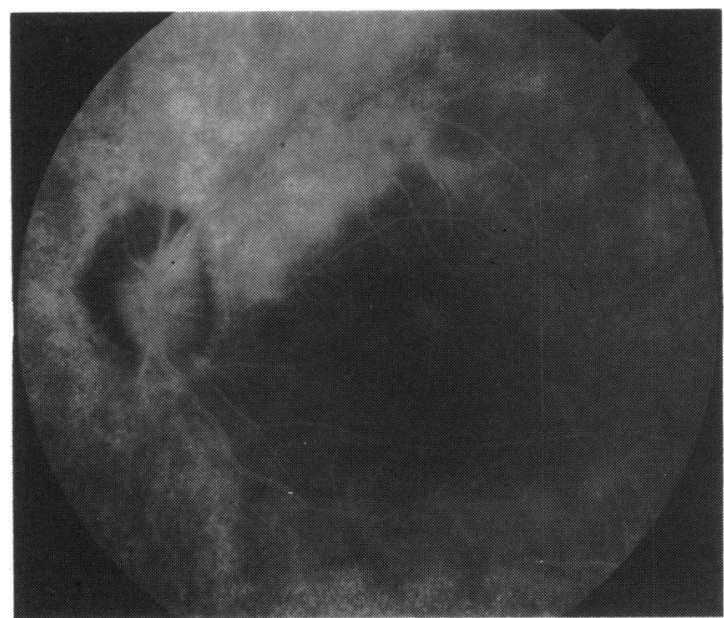

Fig. 1 Case 1, left eye. Fluorescein angiogram shows fluorescein leakage from the choroid and retina, disturbance of the pigment epithelium, and slight macular oedema.

fluorescein leakage from the retinal capillaries in the posterior fundus (Fig. 1). When the vitreous opacity increased, cells appeared in the anterior chamber.

\section{CASE 2}

A 49-year-old woman was admitted to the neurology department in October 1987 because of gait disturbance which had been slowly progressing for the previous five years. She also had sphincter impairment. Her serum and CSF were positive for antibodies to HTLV-I. Her husband and mother were also seropositive for HTLV-I. She was started on an oral corticosteroid preparation for myelopathy in

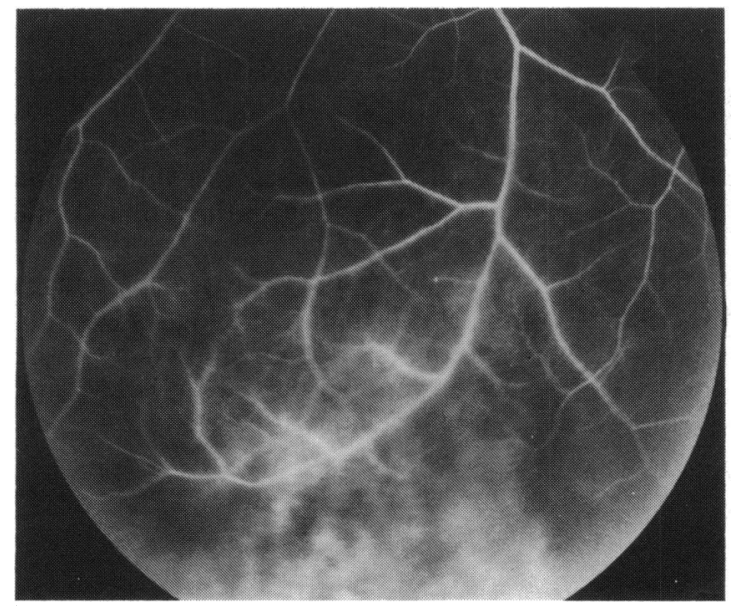

Fig. 2 Case 2, right eye. Fluorescein angiogram shows phlebitis and hyperfluorescent area in the same lesion.
August 1986, and the gait disturbance has been improving.

She was referred to us in September 1987 for investigation of blurred vision in the right eye that had persisted for 10 months. Her visual acuity was 20/25 OD and 20/20 OS. A large number of cells were present in the anterior vitreous in the right eye, and minimal vitreous haze was noted in the left eye. There were also some cells in the anterior chamber of the right eye. Sheathing round the veins and whitish floaters close to the retina were noted in the periphery of the inferior fundus in the right eye. Fluorescein angiogram disclosed phlebitis and hyperfluorescent areas in the same lesions (Fig. 2). During the past year the sheathing round the vein has slowly progressed towards the posterior fundus from the periphery.

\section{CASE 3}

A 50-year-old woman developed pneumonia in March 1987 followed one month later by blurred vision in both eyes. She began to stumble easily and became unable to keep herself in a standing position in August. Gait disturbance had gradually progressed to the point where she was no longer able to walk and stand in October. Sphincter impairment also developed in November. The serum and CSF were positive for antibodies to HTLV-I. She had no history of blood transfusion, and her family history contributed nothing.

When she was first examined in November 1987 her visual acuity was 20/20 in each eye. Many cells were floating in the anterior vitreous of both eyes, though the anterior chamber and lens were clear. Snowball-like opacities were noted in the lower part

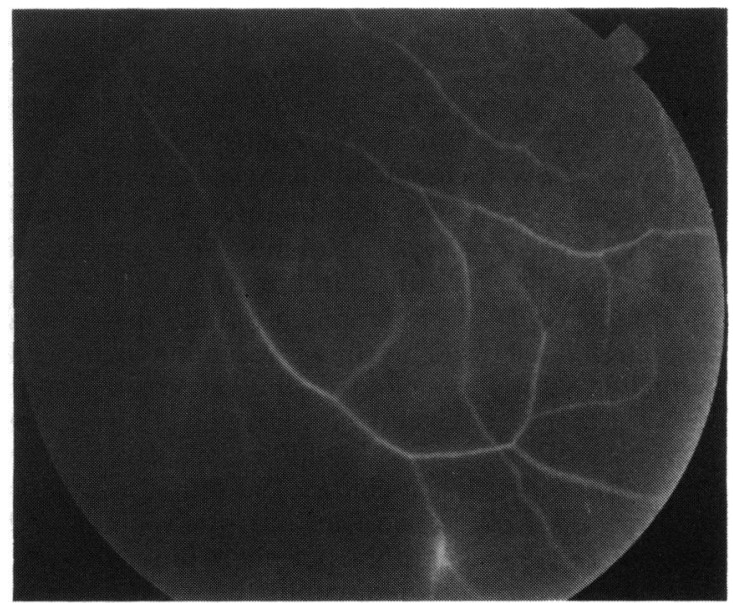

Fig. 3 Case 3, left eye. Fluorescein angiogram shows phlebitis in the periphery of the inferior fundus. 
of the vitreous, and fluorescein angiogram showed phlebitis at 6 o'clock in the periphery of the fundus in the left eye (Fig. 3). There was sheathing of the vein in the periphery of the inferotemporal fundus in the right eye, but a fluorescein angiogram did not show any inflammatory changes. Interferon was given for the myelopathy, and the gait disturbance was slightly improved. It is of interest that retinal vasculitis of the left eye disappeared.

\section{CLINICAL FEATURES OF THE THREE PATIENTS}

The three patients had no lesions in the mucosa or skin (that is, ulceration of the buccal mucosa or external genitalia or erythema nodosum). They had no history of tuberculosis, and chest $x$-rays were normal. The laboratory data showed normal blood counts, blood chemistry, and urine analysis. The levels of angiotensin-converting enzyme in the sera were within the normal range, and serum tests for syphilis, rheumatoid arthritis, and lupus erythematosus were also negative. The serum titres of IgM and IgG antibodies against toxoplasma, herpes zoster, herpes simplex, and cytomegalovirus were low in cases 2 and 3, while IgG antibody against CMV was moderately raised in case 1 . Serum antibody to human immunodeficiency virus was negative in all patients. Anti-HTLV-I antibody titres in both sera and CSF, tested by the particle aggulutination method, were strongly positive.

\section{Discussion}

We examined 12 female patients with slowly progressive myelopathy in whom the disease had its onset in adult life. Anti-HTLV-I antibodies were demonstrated in the sera and CSF of all of them. Further investigation failed to show the cause of the myelopathy, leading to the diagnosis of HTLV-I associated myelopathy (HAM). Among the clinical findings in cases of HAM and HTLV-I associated TSP not only neurological signs but also alveolitis, ${ }^{9}$ Sjögren's syndrome, and keratoconjunctivitis ${ }^{3}$ have been reported. We found retinal vasculitis in three patients with HAM. Two additional patients also presented ocular symptoms with vitreous opacity, though the funduscopic examination, including fluorescein angiography, showed no retinal vasculitis. Although retinal vasculitis extended to the posterior fundus with macular oedema and optic atrophy in case 1 , the periphery of the fundus should be considered to be first involved by the vasculitis. The retinal vasculitis of these patients is characterised by phlebitis and sheathing of the veins at the periphery of the fundus.

As a cause of retinal vasculitis the coexistence of sarcoidosis, Behçet's disease, syphilis, collagen disease, and tuberculosis were ruled out. In case 1,
IgG antibody against CMV was moderately raised. CMV retinitis is usually encountered in the newborn, in patients with an immunodeficient condition as a consequence of treatment for malignancy, or in patients with acquired immune deficiency syndrome (AIDS).${ }^{10}$ However, immunodeficiency is not usually found in HAM patients, and our three patients had no clinical signs to suggest immunosuppression. CMV retinitis has characteristic appearances, including retinal haemorrhage, cotton-wool spots, and necrosis, ${ }^{10}$ which were not observed in case 1 . The raised titre of IgG and the normal level of IgM antibodies against CMV may merely be a sign of past inapparent infection with this virus. Although noninfectious retinal vasculitis may be observed in AIDS, " tests for serum antibody to human immunodeficiency virus were negative in our three patients. The above data suggest that retinal vasculitis is a part of the findings associated with HAM.

The mechanisms for the neurovirulent nature of HTLV-I remain speculative. A slow viral infection may directly infiltrate the nervous system, or an immune reaction provoked by viral infection may attack the nervous system. ${ }^{7}$ Necropsy findings in one HAM patient showed vasculitis in the spinal cord, pons, cerebrum, and cerebellum. ${ }^{12}$ It is of interest that vasculitis could be observed by funduscope in the retina, which is a part of nervous system.

Recent reports have suggested that a retrovirus similar to HTLV-I or III might play a part in the development of multiple sclerosis (MS) ${ }^{13}$ However, the neuropathological features of $\mathrm{HAM}^{12}$ are different from those of MS, and the waxing and waning clinical course in MS is against the slowly progressive nature of HAM. Uveitis has been found in $27 \%$ of MS patients. ${ }^{14}$ They have sheathing of the veins and phlebitis in the periphery of the fundus, which are characterstic findings seen in HAM patients. However, optic neuritis, which is frequently found in MS, was not seen in any of our HAM patients. Optic atrophy, seen in case 1 , was thought to be due to the progression of vasculitis to the posterior aspect of the retina rather than optic neuritis.

There have been few reports of ocular changes associated with HTLV-I. Ophthalmologists working in areas where the infection is endemic need to be aware of eye lesions in patients with HAM and possibly other HTLV-I related diseases.

We thank Dr Kazuo Tamura for his critical comments on the manuscript.

\section{References}

1 Poiesz BJ, Ruscetti FW, Gazdar AF, Bunn PA, Minna JD, Gallo $\mathrm{RC}$. Detection and isolation of type $\mathrm{C}$ retrovirus particles from 
fresh and cultured lymphocytes of a patient with cutaneous T-cell lymphoma. Proc Natl Acad Sci USA 1980; 77: 7415-9.

2 Hinuma Y, Nagata K, Hanaoka M, et al. Adult T-cell leukemia: antigen in an ATL cell line and detection of antibodies to the antigen in human sera. Proc Natl Acad Sci USA 1981; 78: 6476-80.

3 Vernant JC, Maurs L, Gessian A, et al. Endemic tropical spastic paraparesis associated with human T-lymphotropic virus type I: A clinical and seroepidemiological study of 25 cases. Ann Neurol 187: 21: $124-30$.

4 Rodgers-Johnson P, Gajdusek DC, Morgan OStC, Zaninovic V, Sarin PS, Graham DS. HTLV-I and HTLV-III antibodies in tropical spastic paraparesis. Lancet 1985; ii: 1247-8.

5 Roman GC, Schoenberg BS, Madden DL, et al. Human Tlymphotropic virus type I antibodies in the serum of patients with tropical spastic paraparesis in the Seychelles. Arch Neurol 1987; 44: 605-7.

6 Osame M, Arima H, Norimatsu K, et al. HTLV-I associated myelopathy: a new clinical entity. Lancet 1986; i: 1031-2.

7 Osame M, Matsumoto M, Usuki K, et al. Chronic progressive myelopathy associated with elevated antibodies to HTLV-I and adult T-cell leukemia like cells. Ann Neurol 1987; 21: 117-22.
8 Osame M, Igata A, Matsumoto M, Usuku K, Kitajima I, Takahashi K. On the discovery of a new clinical entity: human Tcell lymphotropic virus type I-associated myelopathy (HAM). Adv Neurol Sci 1987; 31: 727-45.

9 Sugimoto M, Nakashima $H$, Watanabe S, et al. T-lymphocyte alveolitis in HTLV-I associated myelopathy. Lancet 1987: ii: 1220.

10 Holland GN, Pepose JS, Pettit TH, Gottlieb MS, Yee RD, Foos RY. Acquired immune deficiency syndrome. Ocular manifestations. Ophthalmology 1983: 90: 859-73.

11 Kestelyn P, Perre PV, Rouvroy D, et al. A prospective study of the ophthalmologic findings in the acquired immune deficiency syndrome in Africa. Am J Ophthalmol 1985; 100: 230-8.

12 Akizuki S, Nakazato O, Higuchi $Y$, et al. Necropsy findings in HTLV-I associated myelopathy. Lancet 1987; i: 156-7.

13 Koprowski H, DeFreitas EC, Harper ME, et al. Multiple sclerosis and human T-cell lymphotropic retroviruses. Nature 1985; 318: 154-60).

14 Breger B, Leopold IH. The incidence of uveitis in multiple sclerosis. Am J Ophthalmol 1972; 62: 540-5.

Accepted for publication 28 April 1989. 